\title{
Evaluation of latent membrane protein 1 and microRNA-155 for the prognostic prediction of diffuse large $B$ cell lymphoma
}

\author{
XUE WU ${ }^{1}$, FEI WANG ${ }^{1}$, YUAN LI $^{2}$, XIYONG WANG ${ }^{2}$, PING LIU $^{1}$, HAIJUN ZHANG $^{3}$, \\ ZHENG GE $^{1}$, XIAOPING ZHANG ${ }^{1}$, CHONG GAO $^{1}$ and BAOAN CHEN ${ }^{1}$ \\ ${ }^{1}$ Department of Hematology (Key Department of Jiangsu Medicine); ${ }^{2}$ Department of Oncology; ${ }^{3}$ Department of Oncology, \\ Medical School, The Affiliated Zhongda Hospital, Southeast University, Nanjing, Jiangsu 210009, P.R. China
}

Received October 26, 2017; Accepted March 16, 2018

DOI: $10.3892 / \mathrm{ol} .2018 .8560$

\begin{abstract}
Diffuse large B cell lymphoma (DLBCL) has previously been demonstrated to contribute to the mortality of lymphoma with various aggressive features. The prognostic role of the biomarkers latent membrane protein (LMP) 1 and microRNA-(miR)-155 in DLBCL remain controversial. The present study primarily aimed to assess the effect of LMP1 and miR-155 on the survival of DLBCL patients, and additionally evaluate the clinical features to observe their influence on outcomes, compared with previous studies. Formalin-fixed and paraffin-embedded samples were collected from our center between May 2010 and December 2011. Microarray analysis, immunohistochemical analysis and reverse transcription-quantitative polymerase chain reaction were used to evaluate the expression of LMP1 and miR-155. The association between biomarkers or clinical features and patient outcomes was assessed using the log-rank statistical test, Cox proportional hazard model and Kaplan-Meier method. SPSS software was used to statistically analyze the data. A total of 82 patients were included in the present study. The results demonstrated that high expression of LMP1 and miR-155 may be associated with a poor progression-free survival rate, while a high International Prognostic Index score and high expression of LMP1 may be associated with a poor overall survival rate. These results indicated that LMP1 and miR-155 may be novel and reliable biomarkers for the prognostic prediction of lymphoma, and will potentially be analyzed in the future to evaluate patient prognosis.
\end{abstract}

Correspondence to: Professor Baoan Chen, Department of Hematology (Key Department of Jiangsu Medicine), Medical School, The Affiliated Zhongda Hospital, Southeast University, 87 Dingjiaqiao, Nanjing, Jiangsu 210009, P.R. China

E-mail: cba8888@hotmail.com

Key words: latent membrane protein 1, lymphoma, microRNA-155, predictor, prognosis

\section{Introduction}

As the most common non-Hodgkin lymphoma, diffuse large B cell lymphoma (DLBCL) contributes to the high mortality rate of lymphoma with its aggressive features, and incidences have increased over the past decades (1). Due to the clinical application of Rituximab, the survival rate of DLBCL patients has improved $(2,3)$. Prognostic factors such as age, clinical symptoms and serum products, once used for predicting the survival of patients, no longer give such a clear indication of survival rate. The efficiency of International Prognostic Index (IPI) may be enhanced by the inclusion of additional prognostic biomarkers during diagnosis (4). Furthermore, chemotherapy treatment is followed by a high incidence of recurrence, which is unable to be prevented by the initial therapeutic strategy, making the predictions more complicated (5). Therefore, prognostic predictors in lymphoma patients may be of considerable value in guiding treatment, or may act as novel therapeutic targets.

MicroRNA-155 (miR-155) has been well established as a hematopoietic oncogene, and is overexpressed in aggressive lympho-proliferative disorders such as DLBCL, Hodgkin lymphoma, Burkitt lymphoma and various types of $\mathrm{T}$ cell lymphomas (6-9). Although the pathological signaling pathway of miR-155 remains to be elucidated, it is a useful biomarker in diagnosis, aiding with therapeutic decisions and prediction outcomes. Various studies have suggested miR-155 has the potential to be a therapeutic target in the treatment of lymphoma (10-12); however, little is known about its specific effect on DLBCL prognosis.

The association between Epstein-Barr virus (EBV) infection and lymphoma has been confirmed by a number of studies (13-15). EBV is present in two forms, similar to other human herpes viruses: Latency and lytic replication. The main EBV latent products include EBV nuclear antigens, latent membrane proteins (LMPs), EBV-encoded small RNAs and miRs (16). It is well demonstrated that viral latent products contribute to oncologic induction. It has been demonstrated that EBV infection is limited to latent phase genes, of which LMP1 is significantly linked to the development of lymphoma as an oncogenic protein (17).

To the best of the authors' knowledge, neither miR-155 or LMP1 has been studied as a survival predictor for any tumor. 
The two have differing expression levels in DLBCL, and are associated with its development. Therefore, the present study aimed to investigate whether the two molecules have an effect on patient outcomes. Formalin-fixed and paraffin-embedded (FFPE) DLBCL samples were collected at our center from May 2010 to April 2015, and the levels of LMP1 and miR-155 were analyzed. The present study aimed to evaluate the association between the data collected patients' outcomes by univariate analysis and multivariate analysis. The results showed that LMP1 and miR-155 had a significantly effect on progression-free survival (PFS) and patient outcomes, and highlighted two reliable biomarkers for the survival prediction of DLBCL.

\section{Materials and methods}

Patients and tissue samples. The study population consisted of a retrospective series of 197 de novo cases of DLBCL obtained from the Affiliated Zhongda Hospital, Southeast University (Nanjing, China), from May 2010 to December 2011. Patients were further selected according to the following eligibility criteria: Diagnosis of pathologically confirmed DLBCL; and treated with CHOP (cyclophosphamide, vincristine, doxorubicin and prednisone) or a CHOP-based regimen. FFPE tumor tissue biopsies were obtained prior to treatment. Acquisition of the patient data was followed-up by the Affiliated Zhongda Hospital, Southeast University, and the samples underwent total RNA of total RNA extraction from FFPE. Overall, 82 patients were analyzed in the current study, and data regarding their clinical features and survival time were collected. Survival time was calculated from the date of diagnosis to the date of event. The date of event was defined as date of death in case of OS, date of progression in case of PFS and right censoring (date of last follow-up without the event). In all cases, the collection of tissues and clinical data of patients was approved by the Affiliated Zhongda Hospital, Southeast University institutional review board. The experiment was undertaken with written informed consent from each patient, and the study conformed with The Code of Ethics of the World Medical Association (Declaration of Helsinki), printed in the British Medical Journal (18 July 1964).

Total RNA extraction from FFPE tissue. The FFPE tissue cores were used for total RNA extraction using an RNAprep Pure FFPE kit (DP439; Tiangen Biotech, Beijing, China) according to the manufacturer's protocol. Xylenes (CAS: 1330-20-7; Macklin Co., Shanghai, China) and absolute ethyl alcohol (CAS: 64-17-5; Macklin Co., Shanghai, China) were used to dissolve the paraffin around the samples.

Microarray analysis. Sample preparation and microarray hybridization were performed by Shanghai Biotechnology Corporation in China (for details, please see 86-021-51320288, project no. BH150192). A total of seven samples, including two of lymphadenitis, two of $\mathrm{T}$ cell lymphoma, one of Hodgkin lymphoma and two of DLBCL, were selected randomly for microarray analysis. The differential expression of miRNAs was identified via fold-change filtering (fold-change $\geq 3.0$ or $\leq 0.5)$ and standard Student's t-test $(\mathrm{P}<0.05)$. The microarray data was calculated using Rstudio (3.3.2 for Windows).
Immunohistochemical (IHC) analysis. An UltraSensitive S-P IHC kit (Maixin, Fuzhou, China) was used for IHC staining, according to the manufacturer's protocol. Sections $(4 \mu \mathrm{m})$ were deparaffinized in a xylene bath for $5 \mathrm{~min}$ at room temperature twice, then subsequently incubated for $5 \mathrm{~min}$ in absolute, $95 \%$, 85 and $70 \%$ ethyl alcohol, then washed with PBS three times for $3 \mathrm{~min}$. The antigen retrieval was performed by incubating the sections in a $0.01 \mathrm{M}$ citrate buffer ( $\mathrm{pH} \mathrm{6.0)}$ ) for $20 \mathrm{~min}$ at $98^{\circ} \mathrm{C}$ and the sections were washed with PBS three times after cooling down. Each section was then incubated with $50 \mu \mathrm{l}$ 3,3'-diaminobenzidine working solution for $10 \mathrm{~min}$ at room temperature, to develop peroxidase activity. A total of $50 \mu 1$ normal non-immune serum was used to block the nonspecific reaction for each section. Following that, the sections were incubated with primary antibody anti-LMP1 (1:100; Santa Cruz Biotechnology, Inc., Dallas, TX, USA) at $4^{\circ} \mathrm{C}$ overnight and washed with PBS three times, prior to incubation with a secondary antibody for $30 \mathrm{~min}$. The sections were then incubated with streptavidin peroxidase solution for $10 \mathrm{~min}$ for coloration, counterstained with hematoxylin and mounted. Then, they were stained using a streptavidin peroxidase system and the signal was visualized using diaminobenzidine substrate.

Reverse transcription-quantitative polymerase chain reaction (RT-qPCR) for LMPI and miR-155 quantification. For each tissue sample, $300 \mathrm{ng}$ total RNA was reverse-transcribed. HiScript II Q RT SuperMix for qPCR (+gDNA wiper) (R223; Vazyme Biotech Co., Ltd., Nanjing, China) was used for LMP1 reverse transcription, and HiScript Q Select RT SuperMix for qPCR (+gDNA wiper) (R133; Vazyme Biotech Co., Ltd.) was used for miR-155 reverse transcription, according to each manufacturer's protocol. ChamQ SYBR qPCR Master Mix (Q311, Vazyme Biotech Co., Ldt.) was used to profile the expression of LMP1 and miR-155 in lymphoid samples. The relative expression levels of mRNAs were normalized to that of the internal control GAPDH for LMP1 and U6 for miR-155. The total RNA from a lymphadenitis tissue sample was used as a control. The primers used were as follows: LMP1 forward, 5'-TGAGCAGGAGGGTGATCATC-3' and reverse, 5'-CTATTCCTTTGCTCTCATGC-3'; hsa-mir155-5p forward, 5'-TTA ATGCTA ATC GTGATA G-3' and reverse, 5'-GTCGTATCCAGTGCAGGGTCCGAGGTATTC GCACTG GAT ACG ACACCC C TA-3'; GAPDH forward, 5'-CCATCACCATCT TCCAGGAG-3' and reverse, 5'-ACAGTCTTCTGGGTGGCAGT-3'; U6 forward, 5'-CTCGCTTCGGCAGCACA-3' and reverse, 5'-AACGCT TCACGAATTTGCG-3'. The cycling conditions were $95^{\circ} \mathrm{C}$ for $30 \mathrm{sec}$, followed by 40 cycles of $95^{\circ} \mathrm{C}$ for $5 \mathrm{sec}$ and $60^{\circ} \mathrm{C}$ for 10 sec. The $\mathrm{Cq}$ value was obtained using ABI StepOne Software (Life Technologies, Foster City, CA, USA). Relative mRNA levels were calculated using $\mathrm{Cq}$ values, and corrected for GAPDH and U6 expression according to the equation $2^{-\Delta \Delta \mathrm{Cq}}(18)$.

Statistical analysis. Univariate survival analysis was performed using a log-rank statistical test, while multivariate survival analysis was performed using a Cox proportional hazard model, to estimate the hazard ratio (HR) for the variables of interest and the $95 \%$ confidence interval (CI) 
A

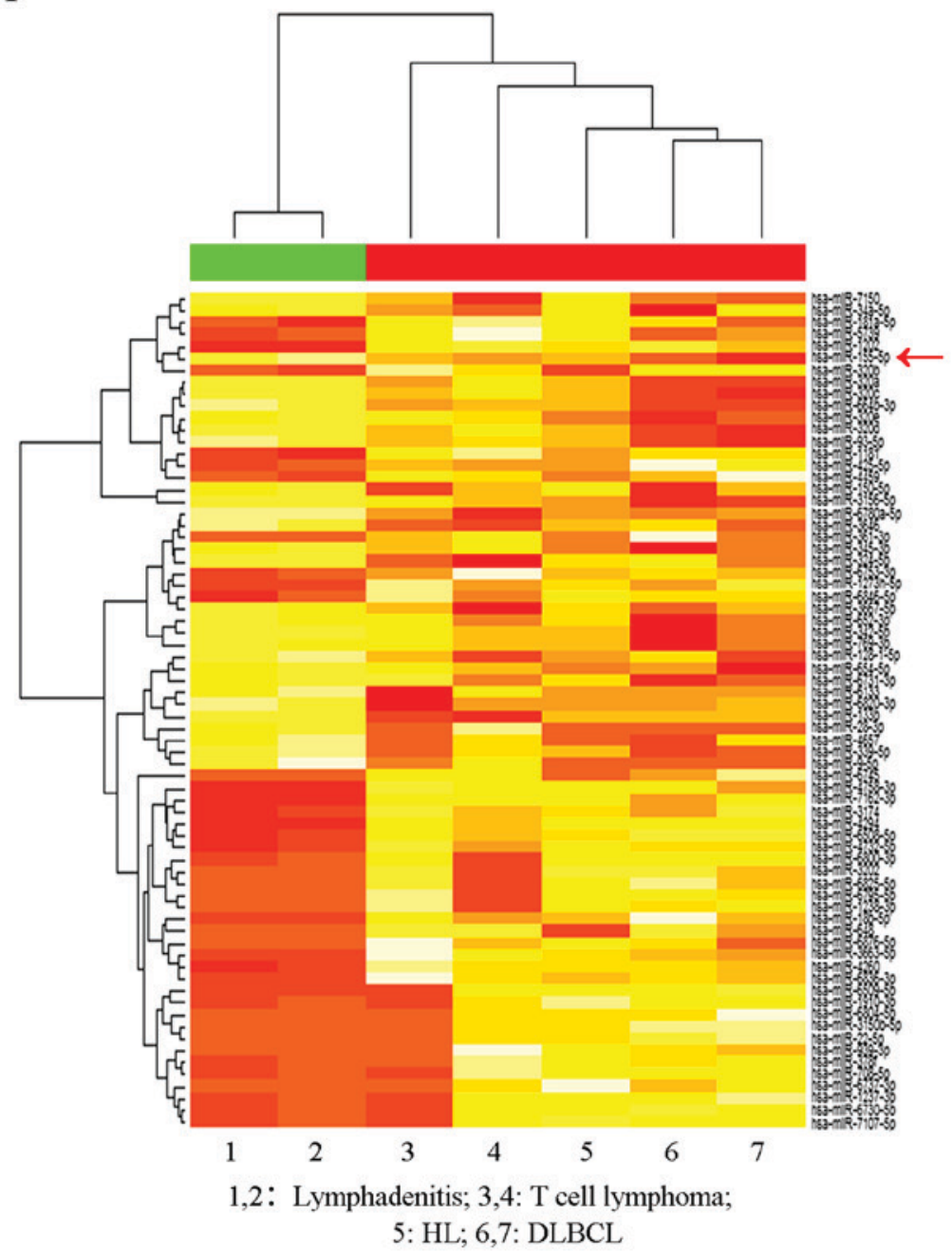

B
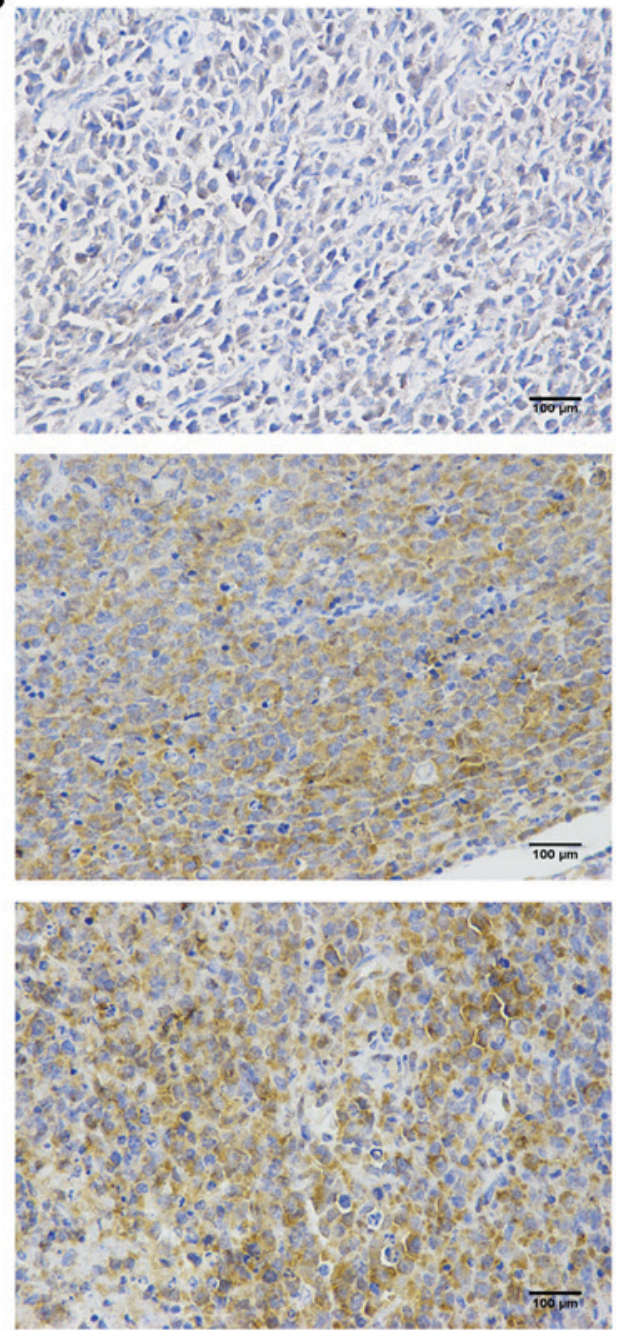

Figure 1. Lymphoma tissue data. (A) A total of 70 miRNAs were detected by microarray in lymphadenitis and lymphoma tissues. Red represents high expression and yellow represents low expression. The miRNA expression variation among the 7 tissues was evaluated by cluster analysis. The expression of miR-155 is labeled with a red arrow. (B) Immunohistochemical analysis of tissues from three lymphoma patients (scale bars, $100 \mu \mathrm{m}$ ). miRNA/miR, microRNA; DLBCL, diffuse large B cell lymphoma; HL, Hodgkin lymphoma.

using SPSS software, version 19.0 (IBM, Inc., Armonk, NY, USA). The Kaplan-Meier method was fitted for the two groups with different biomarkers and the significance for survival difference was assessed by log-rank test. $\mathrm{P}<0.05$ was considered to indicate a statistically significant difference.

\section{Results}

Expression of LMP1 and miR-155 in lymph node tissues. Data obtained from pathological tissues from 82 patients were available for the present study. Of these, two DLBCL tissues were selected randomly for microarray analysis, while two lymphadenitis tissues, two T cell lymphoma tissues and one Hodgkin lymphoma tissue were used as controls and for contrast. A total of 2,550 miRNAs were tested at the initial time and 70 of them were selected for further study according to their fold-change filtering (fold-change $\geq 3.0$ or $\leq 0.5$ ) and the results of the standard Student's t-test $(\mathrm{P}<0.05)$. As presented in Fig. 1A, following clustering analysis, a marked difference was observed between lymphadenitis and lymphoma. Various miRNAs had opposite expression trends in the five lymphoma tissues, compared with the two lymphadenitis tissues, including miR-155, which is labelled with a red arrow. The results revealed that lymphadenitis tissues lacked expression of miR-155, whereas high expression of miR-155 was observed in the samples of lymphoma, and it was particularly high in DLBCL. Therefore, it may be concluded that the increased expression of miR-155 distinguished DLBCL from lymphadenitis and other types of lymphoma.

To assess the expression of LMP1, IHC analysis was conducted for all samples. The results indicated that LMP1 exhibited various expression levels in the different samples (Fig. 1B). Patient 1 was a male patient who was 67 years old. He did not suffer from fever, drenching sweats or weight loss at all. Lactic acid dehydrogenase (LDL) levels in his serum remained normal. However, the lymphoma cells invaded the colon. His Ann Arbor Stage was IV and IPI score was 3. Therefore, he was willing to receive five rounds of Rituximab-CHOP (RCHOP) chemotherapy and planned for auto-HSCT in addition. Patient 2 was a 46 year-old male patient. He had B symptoms of fever with a temperature $>38^{\circ} \mathrm{C}$ and high LDH levels in serum. In addition to this, the lymphoma cells invaded his liver and spleen. 
Table I. Clinical feature according to the biomarkers.

\begin{tabular}{|c|c|c|c|c|c|}
\hline \multirow[b]{2}{*}{ Clinical feature } & \multirow[b]{2}{*}{$\begin{array}{l}\text { All patients } \\
\mathrm{n}=82(\%)\end{array}$} & \multicolumn{2}{|c|}{ LMP1 } & \multicolumn{2}{|c|}{$\operatorname{miR}-155 \Delta$} \\
\hline & & $\begin{array}{c}\text { Positive } \\
(n=41)\end{array}$ & $\begin{array}{l}\text { Negative } \\
(n=41)\end{array}$ & $\begin{array}{l}\text { High } \\
(n=42)\end{array}$ & $\begin{array}{l}\text { Very-high } \\
(n=40)\end{array}$ \\
\hline \multicolumn{6}{|c|}{ Age at diagnosis, $\mathrm{n}(\%)$} \\
\hline$\leq 60$ & $27(33)$ & $12(29)$ & $15(37)$ & $17(40)$ & $10(25)$ \\
\hline$>60$ & $55(67)$ & $29(71)$ & $26(63)$ & $25(60)$ & $30(75)$ \\
\hline \multicolumn{6}{|l|}{ Sex, n (\%) } \\
\hline Male & $48(58)$ & $24(59)$ & $24(59)$ & $26(62)$ & $22(55)$ \\
\hline Female & $34(42)$ & $17(41)$ & $17(41)$ & $16(38)$ & $18(45)$ \\
\hline \multicolumn{6}{|c|}{ Serum LDH level, n (\%) } \\
\hline$\leq 200 \mathrm{U} / 1$ & $52(63)$ & $27(65)$ & $25(61)$ & $26(62)$ & $26(65)$ \\
\hline$>200 \mathrm{U} / 1$ & $30(37)$ & $14(35)$ & $16(39)$ & $16(38)$ & $14(35)$ \\
\hline \multicolumn{6}{|c|}{ B symptoms, n (\%) } \\
\hline Absent & 49 (59) & $24(59)$ & $25(61)$ & $24(57)$ & $25(63)$ \\
\hline Present & $33(41)$ & $17(41)$ & $16(39)$ & $18(43)$ & $15(37)$ \\
\hline \multicolumn{6}{|l|}{ Stage, n (\%) } \\
\hline I & $17(21)$ & $6(15)$ & $11(27)$ & $9(21)$ & $8(20)$ \\
\hline II & $14(17)$ & $7(17)$ & 7 (17) & $7(17)$ & $7(17)$ \\
\hline III & $19(23)$ & $11(27)$ & $8(19)$ & $16(38)$ & $3(8)$ \\
\hline IV & $32(39)$ & $17(41)$ & $15(37)$ & $10(24)$ & $22(55)$ \\
\hline \multicolumn{6}{|l|}{ IPI, n (\%) } \\
\hline 0 & $5(6)$ & $0(0)$ & $5(12)$ & $3(7)$ & $2(5)$ \\
\hline 1 & $18(22)$ & $10(24)$ & 8 (19) & $11(26)$ & 7 (17) \\
\hline 2 & $35(43)$ & $21(51)$ & $14(35)$ & $18(43)$ & $17(43)$ \\
\hline 3 & $14(17)$ & $6(15)$ & 8 (19) & $6(14)$ & $8(20)$ \\
\hline 4 & $10(12)$ & $4(10)$ & $6(15)$ & $4(10)$ & $6(15)$ \\
\hline \multicolumn{6}{|l|}{ ENE, n (\%) } \\
\hline Yes & $45(55)$ & $23(56)$ & $22(54)$ & $18(43)$ & $27(68)$ \\
\hline No & $37(45)$ & $18(44)$ & $19(46)$ & $24(57)$ & $13(32)$ \\
\hline \multicolumn{6}{|c|}{ Rituximab, n (\%) } \\
\hline Yes & $23(28)$ & $8(19)$ & $15(37)$ & $17(40)$ & $6(15)$ \\
\hline No & $59(72)$ & $33(81)$ & $26(63)$ & $25(60)$ & $34(85)$ \\
\hline
\end{tabular}

miR-155 , miR-155 expressed highly in all the lymphoma samples included in this study compared with lymphadenitis. The lymphoma samples were separated into two groups: High ( $\leq 12$ folds) and very-high ( $>12$ folds). miR, microRNA; LMP1, latent membrane protein 1; $\mathrm{LDH}$, lactate dehydrogenase; IPI, international prognostic factors index; ENE, extranodal extension.

His Ann Arbor Stage was IV and IPI score was 2. Unfortunately, the patient did not receive therapy and died two months later. Finally, Patient 3 was a 76 year-old female with EBV (+). She had B symptoms of drenching sweats in addition to fever, but a normal serum LDH level. However, she had extensive extranodal problems in the stomach and pleura. Her Ann Arbor Stage was IV and IPI score was 3. Although this patient was in a poorer condition compared with patients 1 and 2 , she exhibited a partial response after five rounds of RCHOP chemotherapy. The IHC features of these samples demonstrated that the patients who expressed LMP1 accounted for 50\% (41/82) of the total patients.

Clinical features of patients. The clinical characteristics according to the expression of each biomarker are presented in Table I. Patients were categorized into LMP1-positive and LMP1-negative expression groups ( $\mathrm{n}=41$ in each group). However, miR-155 was highly expressed in all patients in the present study. Considering that the variables did not follow a normal distribution in this analysis, in order to evaluate the role of high-expression miR-155 in DLBCL, the present study rearranged the order of the patients according to the expression of miR-155; the median of the patients was revealed (12-fold) and used to divide them into two groups: the high group, which had an expression of miR-155 12-fold lower or equal $(n=42)$; and the very-high group, which had an expression of miR-155 12 -fold higher $(n=40)$. From these groups, we concluded that patients $>60$ years of age accounted for $2 / 3$ of this population, in addition to those with serum LDH levels under or equal 


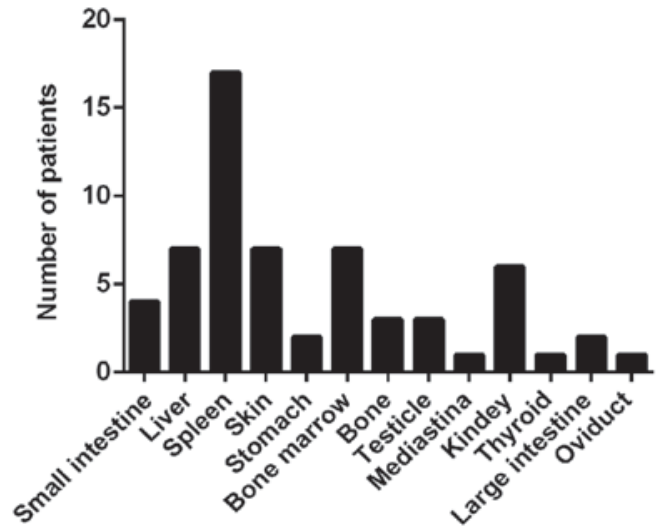

Figure 2. Patients with extranodal extension of organs. Small intestine, $n=4$; liver, $\mathrm{n}=7$; spleen, $\mathrm{n}=17$; skin, $\mathrm{n}=7$; stomach, $\mathrm{n}=2$; bone marrow, $\mathrm{n}=7$; bone, $\mathrm{n}=3$; testicle, $\mathrm{n}=3$; mediastina, $\mathrm{n}=1$; kidney, $\mathrm{n}=6$; thyroid, $\mathrm{n}=1$; large intestine, $\mathrm{n}=2$; oviduct, $\mathrm{n}=1$.
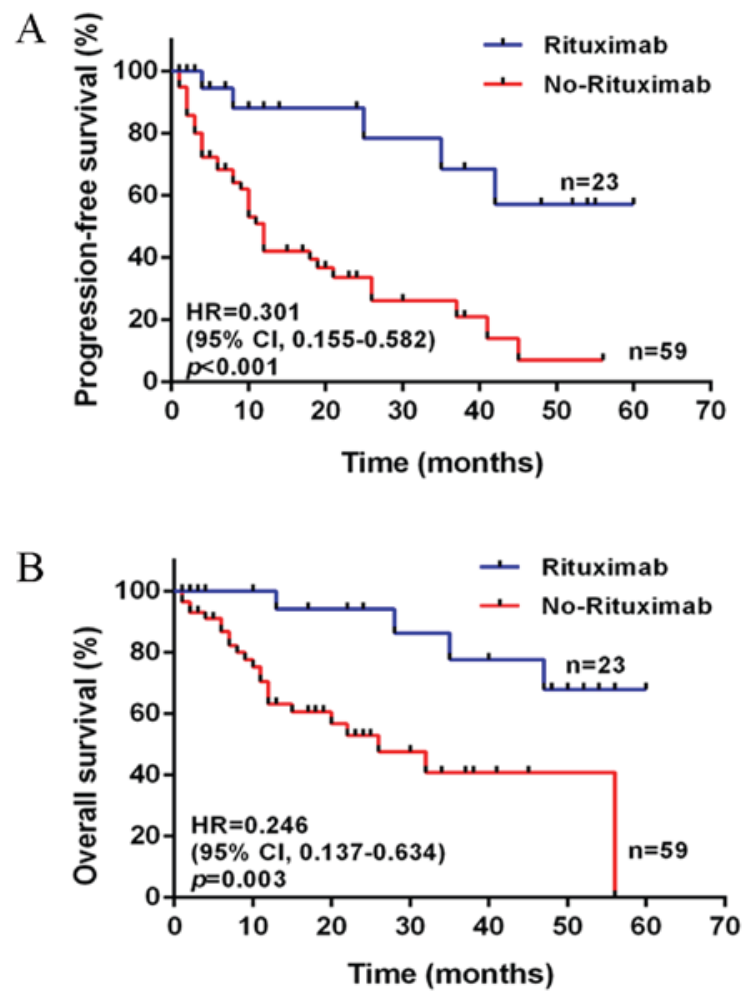

Figure 3. PFS and OS of patients with lymphoma treated with or without Rituximab based on CHOP. (A) The difference between patients treated with RCHOP $(n=23)$ and CHOP $(n=59)$ was statistically significant in PFS $(\mathrm{P}<0.001)$. (B) The difference between patients treated with RCHOP $(n=23)$ and CHOP $(n=59)$ was statistically significant in OS $(P=0.003)$. PFS, progression free survival; OS, overall survival; $\mathrm{CHOP}$, cyclophosphamide, vincristine, doxorubicin and prednisone; R, Rituximab; HR, hazard ratio; CI, confidence interval.

to the normal level. In addition, $>50 \%$ of the patients were at Stage III to IV or IPI 0-2, and most of them had extranodal extension including the spleen, liver, bone marrow and other organs (Fig. 2).

Furthermore, from Table I, it was also observed that a number of patients involved in the present study were treated with Rituximab, accounting for nearly $30 \%$; the others did not receive Rituximab treatment due to a lack of financial support or other non-medical reasons. The patients were separated into two groups: Rituximab $(n=23)$ and non-Rituximab $(n=59)$. Following comparison of their PFS and overall survival (OS), it was concluded that Rituximab markedly improved the outcomes of patients, leading to a longer duration of progression (Fig. 3).

Survival analysis according to expression levels of LMP1 and $m i R-155$. For the patients who were treated with the RCHOP regimen, univariate log-rank analysis identified the significant variables according to the following factors (all of the $\mathrm{P}<0.05$ ): IPI, LMP1 and miR-155 in PFS; LMP1 in OS (Table II). The median follow-up duration was 12 months (range, 1-60). The PFS was better in the IPI 0-2 group compared with the IPI 3-4 group (HR, 0.200; 95\% CI, 0.024-0.822; $\mathrm{P}=0.034$ ) in accordance with previous studies. Furthermore, PFS was additionally influenced by the expression of LMP1 and miR-155. The patients without LMP1 expression usually had a longer PFS and OS duration compared with those who expressed LMP1 (PFS: HR, 0.110; 95\% CI, 0.021-0.593; P=0.012; OS: HR, 0.144; 95\% CI, 0.022-0.844; $\mathrm{P}=0.037$; Fig. 4A and B). However, the results demonstrated that increased expression of miR-155 only had an adverse effect on PFS (HR, 0.183; 95\% CI, 0.021-0.770; P=0.026; Fig. 4C), and was not a predictor of OS (Fig. 4D).

As presented in Table III, for the patients who were treated with a CHOP regimen lacking Rituximab, IPI was identified as a predictive factor only for OS (HR, 0.211; 95\% CI, 0.085-0.461; $\mathrm{P}<0.001)$, but not PFS, by univariate log-rank analysis. The effect of LMP1 and miR-155 on PFS and OS remained the same as that of Rituximab treatment (PFS, LMP1: HR, 0.341; 95\% CI, 0.175-0.634; P=0.001; OS, LMP1: HR, 0.317; 95\% CI, 0.156-0.803; P=0.015; PFS, miR-155: HR, 0.503; 95\% CI, 0.261-0.951; P=0.043; OS, miR-155: HR, 0.409; 95\% CI, 0.190-0.977; P=0.048; Fig. 5). The median follow-up duration was 13 months (range, 1-60).

According to the results of the multivariate analysis, LMP1 and miR-155 were independent factors for PFS (LMP1: HR, 0.165; 95\% CI, 0.063-0.435; P<0.001; miR-155: HR, 0.415; 95\% CI, 0.193-0.891; P=0.024; Table IV), and IPI and LMP1 for OS (IPI: HR, 0.311; 95\% CI, 0.113-0.856, P=0.024; LMP1: HR, 0.208; 95\% CI, 0.064-0.673; P= P0.009; Table IV). It was demonstrated that only LMP1 was a stable predictor for PFS and OS.

\section{Discussion}

The results of the present study demonstrated that the expression of LMP1 was an independent factor for both PFS and OS, whereas miR-155 was significantly associated with PFS. IPI was a predictor for OS in newly diagnosed DLBCL patients, whether they received Rituximab therapy or not. Excluding the influence of other clinical factors, IPI was able to predict the PFS of the patients who were treated with RCHOP, and the OS of the patients who were only treated with CHOP without Rituximab. Furthermore, miR-155 had differing roles in OS according to Rituximab, and the effect of miR-155 on OS was observed in the group of patients treated with Rituximab. Just like it was considered as an independent factor for OS of DLBCL patients. Therefore, it may be concluded that Rituximab resulted in the 
Table II. Univariate analysis for PFS and OS in diffuse large B cell lymphoma patients treated with RCHOP.

\begin{tabular}{|c|c|c|c|c|c|c|}
\hline \multirow[b]{2}{*}{ Variable } & \multicolumn{3}{|c|}{ PFS } & \multicolumn{3}{|c|}{ OS } \\
\hline & HR & $95 \% \mathrm{CI}$ & P-value & HR & $95 \% \mathrm{CI}$ & P-value \\
\hline Age, $\leq 60 />60$ years & 0.671 & $0.103-4.615$ & 0.707 & 0.814 & $0.103-6.434$ & 0.850 \\
\hline Sex, Male/Female & 0.759 & $0.148-3.750$ & 0.728 & 1.155 & $0.199-6.816$ & 0.871 \\
\hline $\mathrm{LDH}, \leq 200 />200 \mathrm{U} / 1$ & 0.449 & $0.043-2.713$ & 0.326 & 1.001 & $0.112-8.950$ & 0.999 \\
\hline B symptom, yes/no & 0.870 & $0.173-4.270$ & 0.858 & 1.001 & $0.167-5.991$ & 0.999 \\
\hline Stage, I-II/III-IV & 0.915 & $0.183-4.517$ & 0.911 & 1.330 & $0.233-7.812$ & 0.746 \\
\hline IPI, 0-2/3-4 & 0.200 & $0.024-0.822$ & $0.034^{\mathrm{a}}$ & 0.291 & $0.034-1.525$ & 0.138 \\
\hline ENE, yes/no & 1.403 & $0.284-7.289$ & 0.669 & 2.098 & $0.376-13.16$ & 0.392 \\
\hline LMP1, positive/negative & 0.110 & $0.021-0.593$ & $0.012^{\mathrm{a}}$ & 0.144 & $0.022-0.844$ & $0.037^{\mathrm{a}}$ \\
\hline miR-155, $\leq 12 />12$ fold high expression & 0.183 & $0.021-0.770$ & $0.026^{\mathrm{a}}$ & 0.263 & $0.029-1.417$ & 0.111 \\
\hline
\end{tabular}

${ }^{\mathrm{a}} \mathrm{P}<0.05$. CI, confidence interval; ENE, extranodal extension; HR, hazard ratio; IPI, international prognostic factors index; LDH, lactate dehydrogenase; LMP1, latent membrane protein 1; miR, microRNA; OS, overall survival; PFS, progression-free survival; RCHOP, Rituximab-cyclophosphamide, vincristine, doxorubicin and prednisone.
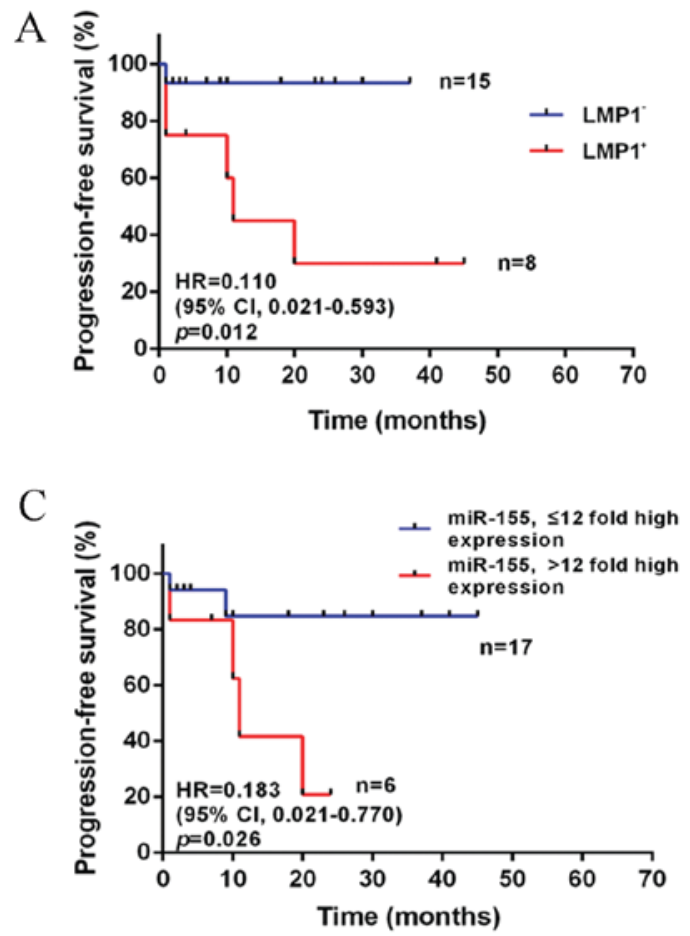

B

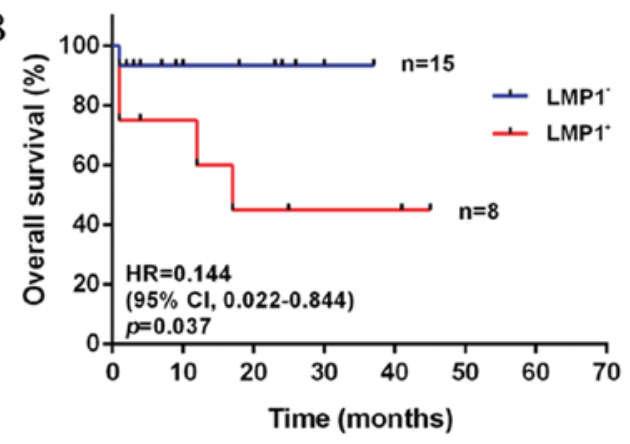

$\mathrm{D}$

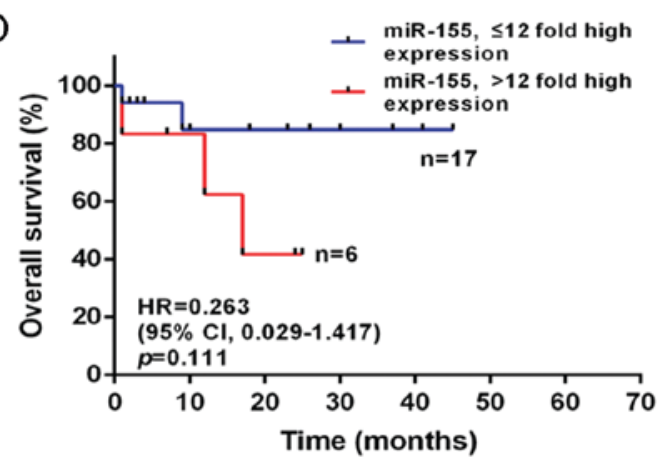

Figure 4. PFS and OS of patients with lymphoma treated with RCHOP according to the expression of LMP1 and miR-155. (A) PFS and (B) OS by LMP1. The difference between patients with $\mathrm{LMP}^{+}(\mathrm{n}=8)$ and $\mathrm{LMP1}^{-}(\mathrm{n}=15)$ was statistically significant in PFS $(\mathrm{P}=0.012)$ and $\mathrm{OS}(\mathrm{P}=0.037)$. (C) PFS and (D) OS by miR-155. The difference between the group of high expression of miR-155 ( $\leq 12$ fold, $n=17)$ and the group of very high expression of miR-155 ( $>12$ fold, $\mathrm{n}=6$ ) was statistically significant in PFS ( $\mathrm{P}=0.026)$; however, not in OS ( $\mathrm{P}=0.111)$. PFS, progression free survival; OS, overall survival; HR, hazard ratio; $\mathrm{CI}$, confidence interval; CHOP, cyclophosphamide, vincristine, doxorubicin and prednisone; R, Rituximab; miRNA/miR, microRNA; LMP-1, latent membrane protein 1.

varied role of IPI and miR-155 in predicting patient outcomes. In the era of Rituximab, the assessment of therapy and prognosis has become a complex procedure. Therefore, in combination with clinical features, biomarkers will play an important role in the prediction of patient outcomes.

Previous studies have presented a variety of conclusions regarding which clinical factors truly affect patient outcomes, with various contradictions among them $(19,20)$. IPI, the only globally used prognostic indicator in B cell lymphoma, was verified to be associated with OS. However, in the Rituximab era, it has failed to predict prognosis in a considerable proportion of patients with B cell lymphoma (21). Therefore, biomarkers seem to be more reliable in evaluating survival along with clinical features. Various factors have previously been identified to alter patient outcomes, including gene mutations in B cell lymphoma-2, MYC, TP53 (22-24), the regulation 
Table III. Univariate analysis for PFS and OS in diffuse large B cell lymphoma patients treated with CHOP.

\begin{tabular}{|c|c|c|c|c|c|c|}
\hline \multirow[b]{2}{*}{ Variable } & \multicolumn{3}{|c|}{ PFS } & \multicolumn{3}{|c|}{ OS } \\
\hline & HR & $95 \% \mathrm{CI}$ & P-value & HR & $95 \% \mathrm{CI}$ & P-value \\
\hline Age, $\leq 60 />60$ years & 0.802 & $0.412-1.562$ & 0.528 & 0.410 & $0.196-1.037$ & 0.065 \\
\hline $\operatorname{Sex}, \mathrm{M} / \mathrm{F}$ & 1.278 & $0.672-2.494$ & 0.458 & 1.731 & $0.744-3.875$ & 0.215 \\
\hline $\mathrm{LDH}, \leq 200 />200 \mathrm{U} / 1$ & 1.063 & $0.553-2.069$ & 0.849 & 0.761 & $0.321-1.744$ & 0.508 \\
\hline B symptom, yes/no & 0.720 & $0.364-1.338$ & 0.308 & 0.716 & $0.288-1.671$ & 0.423 \\
\hline Stage, I-II/III-IV & 0.861 & $0.442-1.637$ & 0.644 & 0.873 & $0.376-2.024$ & 0.753 \\
\hline IPI, 0-2/3-4 & 0.647 & $0.310-1.193$ & 0.165 & 0.211 & $0.085-0.461$ & $<0.001^{\mathrm{b}}$ \\
\hline ENE, yes/no & 0.608 & $0.309-1.123$ & 0.120 & 0.688 & $0.302-1.552$ & 0.372 \\
\hline LMP1, positive/negative & 0.341 & $0.175-0.634$ & $0.001^{\mathrm{b}}$ & 0.317 & $0.156-0.803$ & $0.015^{\mathrm{a}}$ \\
\hline miR-155, $\leq 12 />12$ fold high expression & 0.503 & $0.261-0.951$ & $0.043^{\mathrm{a}}$ & 0.409 & $0.190-0.977$ & $0.048^{\mathrm{a}}$ \\
\hline
\end{tabular}

${ }^{\mathrm{a}} \mathrm{P}<0.05$; ${ }^{\mathrm{b}} \mathrm{P}<0.001$. CI, confidence interval; ENE, extranodal extension; HR, hazard ratio; IPI, international prognostic factors index; LDH, lactate dehydrogenase; LMP1, latent membrane protein 1; miR, microRNA; OS, overall survival; PFS, progression-free survival; CHOP, cyclophosphamide, vincristine, doxorubicin and prednisone.

\section{A}

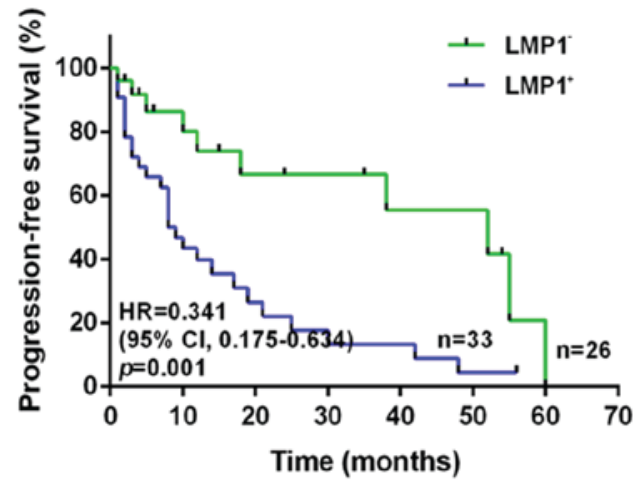

C

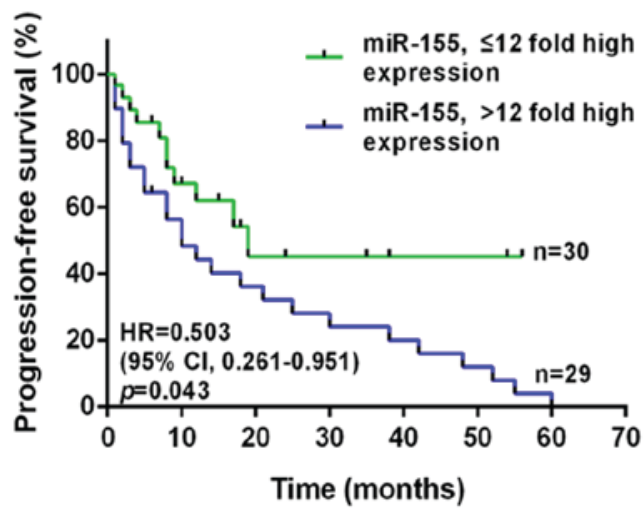

$\mathrm{B}$

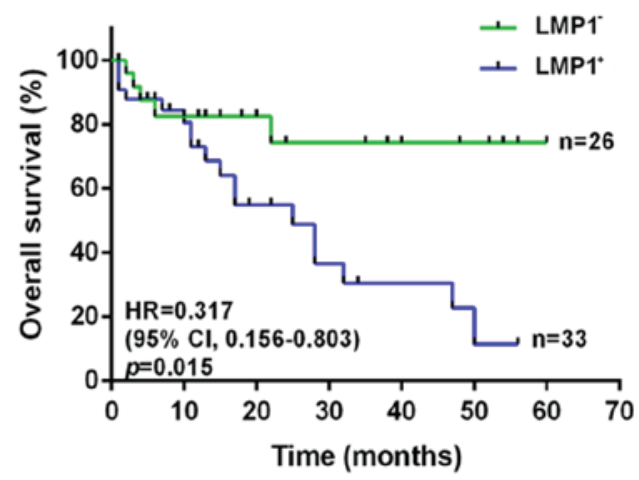

$\mathrm{D}$

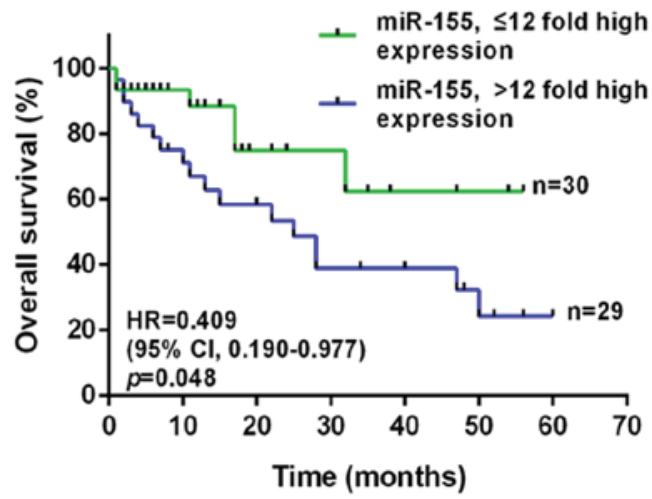

Figure 5. PFS and OS of patients with lymphoma treated with CHOP according to the expression of LMP1 and miR-155. (A) PFS and (B) OS by LMP1. The difference between patients with $\mathrm{LMP}^{+}(\mathrm{n}=33)$ and $\mathrm{LMP1}^{-}(\mathrm{n}=26)$ was statistically significant in PFS $(\mathrm{P}=0.001)$ and $\mathrm{OS}(\mathrm{P}=0.015)$. (C) PFS and (D) OS by miR-155. The difference between the group of high expression of miR-155 ( $\leq 12$ fold, $n=30)$ and the group of very high expression of miR-155 ( $>12$ fold, $n=29)$ was statistically significant in PFS ( $\mathrm{P}=0.043)$ and $\mathrm{OS}(\mathrm{P}=0.048)$. PFS, progression free survival; OS, overall survival; CHOP, cyclophosphamide, vincristine, doxorubicin and prednisone; miRNA/miR, microRNA; HR, hazard ratio; CI, confidence interval; LMP-1, latent membrane protein 1.

of miRNAs including miR-155, miR-21 and miR-124 (25-27), and the expression of virus-infected relative genes $(28,29)$. Accumulating evidence has revealed that the expression of miR-155 may be a key biomarker in the development of lymphoma (25). miR-155-5p was also observed to be increased in Hodgkin's lymphoma, and contributed to development of the disease (30). Additionally, in indolent primary cutaneous B-cell lymphoma, Monsálvez et al (31) evaluated the association between miR-155 expression and PFS (31).

In addition to miRNAs, the expression of LMP1, which results from EBV infection, may induce the development of lymphoma $(32,33)$. The prognostic value of LMP1 remains 
Table IV. Multivariate analysis for PFS and OS in patients with diffuse large B cell lymphoma patients.

\begin{tabular}{|c|c|c|c|c|c|c|}
\hline \multirow[b]{2}{*}{ Variable } & \multicolumn{3}{|c|}{ PFS } & \multicolumn{3}{|c|}{ OS } \\
\hline & HR & $95 \% \mathrm{CI}$ & P-value & HR & $95 \% \mathrm{CI}$ & P-value \\
\hline Age,$\leq 60 />60$ years & 1.529 & $0.586-3.984$ & 0.385 & 1.432 & $0.428-4.797$ & 0.560 \\
\hline $\operatorname{Sex}, \mathrm{M} / \mathrm{F}$ & 0.908 & $0.443-1.859$ & 0.791 & 0.521 & $0.192-1.415$ & 0.201 \\
\hline $\mathrm{LDH}, \leq 200 />200 \mathrm{U} / 1$ & 0.583 & $0.256-1.330$ & 0.200 & 0.405 & $0.140-1.171$ & 0.095 \\
\hline B symptom, yes/no & 1.081 & $0.451-2.591$ & 0.861 & 1.077 & $0.373-3.108$ & 0.890 \\
\hline Stage, I-II/III-IV & 2.130 & $0.922-4.922$ & 0.077 & 2.043 & $0.784-5.320$ & 0.144 \\
\hline IPI, 0-2/3-4 & 0.719 & $0.333-1.550$ & 0.400 & 0.311 & $0.113-0.856$ & $0.024^{\mathrm{a}}$ \\
\hline ENE, yes/no & 0.979 & $0.473-2.027$ & 0.954 & 0.877 & $0.441-2.611$ & 0.877 \\
\hline LMP1, positive/negative & 0.165 & $0.063-0.435$ & $<0.001^{\mathrm{c}}$ & 0.208 & $0.064-0.673$ & $0.009^{b}$ \\
\hline $\operatorname{miR}-155, \leq 12 />12$ fold high expression & 0.415 & $0.193-0.891$ & $0.024^{\mathrm{a}}$ & 0.445 & $0.174-1.136$ & 0.090 \\
\hline
\end{tabular}

${ }^{\mathrm{a}} \mathrm{P}<0.05$; ${ }^{\mathrm{b}} \mathrm{P}<0.01$; and ${ }^{\mathrm{c}} \mathrm{P}<0.001$. CI, confidence interval; ENE, extranodal extension; HR, hazard ratio; IPI, international prognostic factors index; LDH, lactate dehydrogenase; LMP1, latent membrane protein 1; miR, microRNA; OS, overall survival; PFS, progression-free survival.

controversial, as the majority of studies are limited to a small number of recruited patients. In 2012, a study including 16 extranodal natural killer (NK)/T-cell lymphoma (ENKTL) patients demonstrated that LMP1 exhibited a significant correlation with patient OS, thus LMP1 may be a prognostic indicator of survival in lymphoma patients (34). Furthermore, Bi et al (35) indicated that LMP1 upregulated PD-L1 through the nuclear factor- $\kappa \mathrm{B}$ pathway (induced by EBV), and this was associated with the poor prognosis of lymphoma. This result suggested that LMP1 may act as a prognostic predictor.

Notably, these studies presented a partial association as they focused primarily on the mechanisms regarding LMP1 and miR-155 functioning in the process of lymphoma development. Hence, in order to evaluate the effect of these biomarkers on prognosis, further data from patients should be recruited and evaluated. The present retrospective analysis was designed to collect information from DLBCL patients and give a general conclusion regarding the association between particular biomarkers and patient survival outcomes. The results verified that the expression levels of LMP1 and miR-155 were associated with poor prognosis of patients, indicating these two biomarkers as efficient predictors of PFS and OS, supported by their oncogenic functions.

The present study demonstrated the favorable impact and clinical value of LMP1 and miR-155 expression on the PFS and OS of patients with newly diagnosed lymphoma, suggesting that LMP1 and miR-155 should be analyzed to evaluate patient prognosis as integral biomarkers. The limitations of the present study included the relatively small number of patients included and the lack of available data on the EBV-DNA in cells. Furthermore, the expression of LMP1 was based on EBV infection, whereas not all EBV infected lymphomas would induce LMP1. In addition, in China there are different and more aggressive LMP1 variants, which may occur due to genetic polymorphisms of the LMP1 oncogene. Specific sets of point mutations I124 V/I152L and F144I/D150A/L151, associated with high nuclear factor-kB activation, may occur (36), as well as the presence of 30 and 69 bp deletions (37). The genetic polymorphisms of the
LMP1 oncogene were not analyzed here. These should be considered in an in-depth analysis of the exact function of LMP1 in DLBCL in the future. The prognostic values of LMP1 expression appear to be more sensitive and accurate and after more patients are enrolled in the future studies, a comparison between EBV and LMP1 may be performed. Samples will also be collected samples from other places, making it a multiple center study, in order to obtain a more reliable result.

\section{Acknowledgements}

Not applicable.

\section{Funding}

The present study was supported by The National Natural Science Foundation of China (grant no. 81370673), Key Medical Subjects of Jiangsu Province (grant no. BL2014078), Key Discipline of Jiangsu Province (2016-2020) and and Jiangsu Provincial Medical Youth Talent (grant no. QNRC2016812).

\section{Availability of data and materials}

The datasets used and/or analyzed during the current study are available from the corresponding author on reasonable request.

\section{Authors' contributions}

XW and FW collected the patient data associated with hematological disease. XW and YL analyzed the microarray data. XW and XYW collected the FFPE samples, performed the histological examination and analyzed the data. PL, ZG and XPZ conducted the statistical analysis. BC contributed to the conception and design of the study, and gave final approval for the manuscript to be published. CG performed the collection of patient information, and HJZ assisted with the IHC analysis. $\mathrm{BC}, \mathrm{CG}$ and $\mathrm{HJZ}$ were responsible for revising the manuscript. All authors read and approved the final manuscript. 


\section{Ethics approval and consent to participate}

The present study was undertaken with written informed consent from each patient, and the collection of tissues and clinical data of patients was approved by the Affiliated Zhongda Hospital, Southeast University institutional review board.

\section{Consent for publication}

The patient provided written informed consent for the publication of any associated data and accompanying images.

\section{Competing interests}

The authors declare that they have no competing interests.

\section{References}

1. Siegel RL, Miller KD and Jemal A: Cancer statistics, 2016. CA Cancer J Clin 66: 7-30, 2016

2. Westin JR, McLaughlin P, Romaguera J, Hagemeister FB, Pro B, Dang NH, Samaniego F, Rodriguez MA, Fayad L, Oki Y, et al: Paclitaxel, topotecan and rituximab: Long term outcomes of an effective salvage programme for relapsed or refractory aggressive B-cell non-Hodgkin lymphoma. Br J Haematol 167: 177-184, 2014.

3. Lee GW, Go SI, Kim SH, Hong J, Kim YR, Oh S, Kim SY, Do YR, Lee H, Lee SI, et al: Clinical outcome and prognosis of patients with primary sinonasal tract diffuse large B-cell lymphoma treated with rituximab-cyclophosphamide, doxorubicin, vincristine and prednisone chemotherapy: A study by the Consortium for Improving Survival of Lymphoma. Leuk Lymphoma 56: 1020-1026, 2015.

4. Park JH, Yoon DH, Kim DY, Kim S, Seo S, Jeong Y, Lee SW, Park CS, Huh J and Suh C: The highest prognostic impact of LDH among international prognostic indices (IPIs): An explorative study of five IPI factors among patients with DLBCL in the era of rituximab. Ann Hematol 93: 1755-1764, 2014.

5. Cohen JB, Behera M, Thompson CA and Flowers CR: Evaluating surveillance imaging for diffuse large B-cell lymphoma and Hodgkin lymphoma. Blood 129: 561-564, 2017.

6. Jones K, Nourse JP, Keane C, Bhatnagar A and Gandhi MK: Plasma microRNA are disease response biomarkers in classical Hodgkin lymphoma. Clin Cancer Res 20: 253-264, 2014

7. Eis PS, Tam W, Sun L, Chadburn A, Li Z, Gomez MF, Lund E and Dahlberg JE: Accumulation of miR-155 and BIC RNA in human B cell lymphomas. Proc Natl Acad Sci USA 102: 3627-3632, 2005.

8. Iqbal J, Shen Y, Huang X, Liu Y, Wake L, Liu C, Deffenbacher K, Lachel CM, Wang C, Rohr J, et al: Global microRNA expression profiling uncovers molecular markers for classification and prognosis in aggressive B-cell lymphoma. Blood 125: 1137-1145, 2015.

9. Gracias DT, Stelekati E, Hope JL, Boesteanu AC, Doering TA, Norton J, Mueller YM, Fraietta JA, Wherry EJ, Turner M and Katsikis PD: The microRNA miR-155 controls CD8(+) T cell responses by regulating interferon signaling. Nat Immunol 14 593-602, 2013

10. Huskova H, Korecka K, Karban J, Vargova J, Vargova K, Dusilkova N, Trneny M and Stopka T: Oncogenic microRNA-155 and its target PU.1: An integrative gene expression study in six of the most prevalent lymphomas. Int J Hematol 102: 441-450, 2015.

11. Zeng Q, Tao X, Huang F, Wu T, Wang J, Jiang X, Kuang Z and Cheng B: Overexpression of miR-155 promotes the proliferation and invasion of oral squamous carcinoma cells by regulating BCL6/cyclin D2. Int J Mol Med 37: 1274-1280, 2016.

12. Lv L, An X, Li H and Ma L: Effect of miR-155 knockdown on the reversal of doxorubicin resistance in human lung cancer A549/dox cells. Oncol Lett 11: 1161-1166, 2016.

13. McLaughlin LP, Gottschalk S, Rooney CM and Bollard CM: EBV-directed T cell therapeutics for EBV-associated lymphomas. Methods Mol Biol 1532: 255-265, 2017.
14. Ghosh Roy S, Robertson ES and Saha A: Epigenetic Impact on EBV Associated B-Cell Lymphomagenesis. Biomolecules 6: pii: E46, 2016.

15. Mackrides N, Campuzano-Zuluaga G, Maque-Acosta Y, Moul A, Hijazi N, Ikpatt FO, Levy R, Verdun RE, Kunkalla K, Natkunam Y, et al: Epstein-Barr virus-positive follicular lymphoma. Mod Pathol 30: 519-529, 2017.

16. Raab-Traub N: EBV-induced oncogenesis. In: Human Herpesviruses: Biology, Therapy and Immunoprophylaxis. Arvin A, Campadelli-Fiume G, Mocarski E, Moore PS, Roizman B, Whitley R and Yamanishi K (eds). Cambridge University Press 2007. Cambridge, 2007.

17. Huang YC, Lin SJ, Lin KM, Chou YC, Lin CW, Yu SC, Chen CL, Shen TL, Chen CK, Lu J, et al: Regulation of EBV LMP1-triggered EphA4 downregulation in EBV-associated B lymphoma and its impact on patients' survival. Blood 128: 1578-1589, 2016.

18. Livak KJ and Schmittgen TD: Analysis of relative gene expression data using real-time quantitative PCR and the 2(-Delta Delta C(T)) method. Methods 25: 402-408, 2001.

19. Shen Y, Zhang R, Liu L, Shen Y, Song W, Qi T, Tang Y, Wang Z, Guan $\mathrm{L}$ and $\mathrm{Lu} \mathrm{H}$ : Clinical and prognostic analysis of 78 patients with human immuno-deficiency virus associated non-Hodgkin's lymphoma in Chinese population. Infect Agent Cancer 12: 7 , 2017.

20. Mukhtar F, Boffetta P, Risch HA, Park JY, Bubu OM, Womack L, Tran TV, Zgibor JC and Luu HN: Survival predictors of Burkitt's lymphoma in children, adults and elderly in the United States during 2000-2013. Int J Cancer 140: 1494-1502, 2016.

21. Öztürk E, Özbalak M, Berk S, Erdoğan I, Avşar E, Dolgun A, Çetiner M, Mandel NM, Yalnız FF, Elverdi T, et al: Comparison of international prognostic index and NCCN-IPI in 324 patients with de novo diffuse large B-cell lymphoma: A multi-center retrospective analysis. Leuk Lymphoma 57: 1211-1214, 2016

22. Sesques P and Johnson NA: Approach to the diagnosis and treatment of high-grade B-cell lymphomas with MYC and BCL2 and/or BCL6 rearrangements. Blood 129: 280-288, 2017.

23. Cao Y, Zhu T, Zhang P, Xiao M, Yi S, Yang Y, Li Q, Ling S, Wang Y, Gao L, et al: Mutations or copy number losses of CD58 and TP53 genes in diffuse large B cell lymphoma are independent unfavorable prognostic factors. Oncotarget 7: 83294-83307, 2016.

24. Zamani-Ahmadmahmudi M, Aghasharif S and Ilbeigi K: Prognostic efficacy of the human B-cell lymphoma prognostic genes in predicting disease-free survival (DFS) in the canine counterpart. BMC Vet Res 13: 17, 2017.

25. Due H, Svendsen P, Bodker JS, Schmitz A, Bøgsted M, Johnsen HE, El-Galaly TC, Roug AS and Dybkær K: miR-155 as a Biomarker in B-Cell Malignancies. Biomed Res Int 2016: 9513037, 2016.

26. Li J, Fu R, Yang L and Tu W: miR-21 expression predicts prognosis in diffuse large B-cell lymphoma. Int J Clin Exp Pathol 8: $15019-15024,2015$.

27. Jeong D, Kim J, Nam J, Sun H, Lee YH, Lee TJ, Aguiar RC and Kim SW: MicroRNA-124 links p53 to the NF- $\kappa$ B pathway in B-cell lymphomas. Leukemia 29: 1868-1874, 2015.

28. Chang KC, Chen PC, Chang Y, Wu YH, Chen YP, Lai CH, Medeiros LJ, Su IJ and Wang HW: Epstein-Barr virus latent membrane protein-1 up-regulates cytokines and correlates with older age and poorer prognosis in Hodgkin lymphoma. Histopathology 70: 442-455, 2017.

29. Olszewski AJ, Fallah J and Castillo JJ: Human immunodeficiency virus-associated lymphomas in the antiretroviral therapy era: Analysis of the National Cancer Data Base. Cancer 122: 2689-2697, 2016

30. Paydas S, Acikalin A, Ergin M, Celik H, Yavuz B and Tanriverdi K: Micro-RNA (miRNA) profile in Hodgkin lymphoma: Association between clinical and pathological variables. Med Oncol 33: 34, 2016.

31. Monsálvez V, Montes-Moreno S, Artiga MJ, Rodríguez ME, Sanchez-Espiridion B, Lozano M, Fernández-de-Misa R, Rodríguez-Peralto JL, Piris MA and Ortíz-Romero PL: MicroRNAs as prognostic markers in indolent primary cutaneous B-cell lymphoma. Mod Pathol 26: 171-181, 2013.

32. Lajoie V, Lemieux B, Sawan B, Lichtensztejn D, Lichtensztejn Z, Wellinger R, Mai S and Knecht H: LMP1 mediates multinuclearity through downregulation of shelterin proteins and formation of telomeric aggregates. Blood 125: 2101-2110, 2015. 
33. Bollard CM, Gottschalk S, Torrano V, Diouf O, Ku S, Hazrat Y, Carrum G, Ramos C, Fayad L, Shpall EJ, et al: Sustained complete responses in patients with lymphoma receiving autologous cytotoxic T lymphocytes targeting Epstein-Barr virus latent membrane proteins. J Clin Oncol 32: 798-808, 2014

34. Mao Y, Zhang DW, Zhu H, Lin H, Xiong L, Cao Q, Liu Y, Li QD, Xu JR, Xu LF and Chen RJ: LMP1 and LMP2A are potential prognostic markers of extranodal NK/T-cell lymphoma, nasal type (ENKTL). Diagn Pathol 7: $178,2012$.

35. Bi XW, Wang H, Zhang WW, Wang JH, Liu WJ, Xia ZJ, Huang HQ, Jiang WQ, Zhang YJ and Wang L: PD-L1 is upregulated by EBV-driven LMP1 through NF- $\mathrm{KB}$ pathway and correlates with poor prognosis in natural killer/T-cell lymphoma. J Hematol Oncol 9: 109, 2016.
36. ZuercherE,ButticazC,WynigerJ,MartinezR,BattegayM,BoffiEl Amari E, Dang T, Egger JF, Fehr J, Mueller-Garamvögyi E, et al: Genetic diversity of EBV-encoded LMP1 in the Swiss HIV Cohort Study and implication for NF-Kb activation. PLoS One 7: e32168, 2012.

37. Knecht H, Berger C, Rothenberger S, Odermatt BF and Brousset P: The role of Epstein-Barr virus in neoplastic transformation. Oncology 60: 289-302, 2001.

(i) $(9)$ This work is licensed under a Creative Commons Attribution-NonCommercial-NoDerivatives 4.0 International (CC BY-NC-ND 4.0) License. 